\title{
Differential expression of cysteine desulfurases in soybean
}

\author{
Marta D Heis ${ }^{1}$, Elisabeth M Ditmer ${ }^{1}$, Luisa A de Oliveira ${ }^{1}$, Ana Paula G Frazzon², Rogério Margis ${ }^{1}$ and \\ Jeverson Frazzon ${ }^{3 *}$
}

\begin{abstract}
Background: Iron-sulfur [Fe-S] clusters are prosthetic groups required to sustain fundamental life processes including electron transfer, metabolic reactions, sensing, signaling, gene regulation and stabilization of protein structures. In plants, the biogenesis of Fe-S protein is compartmentalized and adapted to specific needs of the cell. Many environmental factors affect plant development and limit productivity and geographical distribution. The impact of these limiting factors is particularly relevant for major crops, such as soybean, which has worldwide economic importance.
\end{abstract}

Results: Here we analyze the transcriptional profile of the soybean cysteine desulfurases NFS1, NFS2 and ISD11 genes, involved in the biogenesis of [Fe-S] clusters, by quantitative RT-PCR. NFS1, ISD11 and NFS2 encoding two mitochondrial and one plastid located proteins, respectively, are duplicated and showed distinct transcript levels considering tissue and stress response. NFS1 and ISD11 are highly expressed in roots, whereas NFS2 showed no differential expression in tissues. Cold-treated plants showed a decrease in NFS2 and ISD11 transcript levels in roots, and an increased expression of NFS1 and ISD11 genes in leaves. Plants treated with salicylic acid exhibited increased NFS1 transcript levels in roots but lower levels in leaves. In silico analysis of promoter regions indicated the presence of different cis-elements in cysteine desulfurase genes, in good agreement with differential expression of each locus. Our data also showed that increasing of transcript levels of mitochondrial genes, NFS1/ISD11, are associated with higher activities of aldehyde oxidase and xanthine dehydrogenase, two cytosolic Fe-S proteins.

Conclusions: Our results suggest a relationship between gene expression pattern, biochemical effects, and transcription factor binding sites in promoter regions of cysteine desulfurase genes. Moreover, data show proportionality between NFS1 and ISD11 genes expression.

\section{Background}

[Fe-S] clusters may be the most ancient and versatile inorganic cofactors in biological systems. They can be found in all living organisms, participating in electron transfer, catalysis and regulatory processes. Besides, [FeS] clusters are involved in sensing environmental stimuli and regulation of protein expression [1-3]. In plants, the biogenesis of $\mathrm{Fe}-\mathrm{S}$ proteins is compartmentalized and mostly adapted to the requirements of the green tissue, which carries out both photosynthesis and respiration, processes that require significant amounts of $\mathrm{Fe}-\mathrm{S}$ proteins. Mitochondria and plastid have their own

\footnotetext{
* Correspondence: jeverson.frazzon@ufrgs.br

${ }^{3}$ Department of Food Science, Federal University of Rio Grande do Sul -

UFRGS, Porto Alegre, RS, Brazil

Full list of author information is available at the end of the article
}

machineries for $[\mathrm{Fe}-\mathrm{S}]$ cluster assembly, which differ in biochemical and genetic properties. Among the Fe-S proteins known in plant mitochondria are complexes I, II and III of the respiratory chain and aconitase of the citric acid cycle, and in plastids are cytochrome $b_{6} f$ complex, photosystem I and ferredoxin-thioredoxin reductase [4-7].

Three different systems for [Fe-S] clusters biosynthesis have been identified in bacteria, all of them share cysteine desulfurases and [Fe-S] cluster scaffold proteins. Those systems are referred to as NIF (nitrogen fixation system), ISC (iron-sulfur cluster assembly system) and SUF (sulfur mobilization system) [8-10]. There are several mitochondrial proteins homologous to the bacterial ISC system, including a group I NifS-like proteins, supporting the evolutionary relationship between $\alpha$
C Biomed Central

(C) 2011 Heis et al; licensee BioMed Central Ltd. This is an Open Access article distributed under the terms of the Creative Commons Attribution License (http://creativecommons.org/licenses/by/2.0), which permits unrestricted use, distribution, and reproduction in any medium, provided the original work is properly cited. 
Proteobacteria and mitochondria [5]. In yeast, it has been shown that mitochondria are the primary site of [Fe-S] cluster formation; however, these organelles not only produce their own Fe-S proteins, but are also required for the maturation of cytosolic Fe-S proteins [11]. In the chloroplast, five different [Fe-S] cluster types are found in various proteins, and this organelle possesses its own machinery for [Fe-S] biosynthesis which is most similar to those found in cyanobacteria containing the SUF system and the cysteine desulfurase which is similar to the bacterial SufS, a group II NifS-like protein $[12,13]$.

Cysteine desulfurase is a pyridoxal 5'-phosphate (PLP)dependent enzyme that catalyzes the conversion of Lcysteine to L-alanine and sulfane sulfur. This occurs through the formation of a protein-bound cysteine persulfide intermediate on a conserved cysteine residue $[14,15]$. Considering that sulfide and free iron are toxic to the cell, intracellular concentrations are thought to be extremely low. Besides being involved in sulfur mobilization, cysteine desulfurase is proposed to be involved in cellular iron homeostasis [16-18]. ISD11 is an essential mitochondria matrix protein, a component of the ISC-assembly machinery, and is conserved in eukaryotes, but not found in prokaryotes. This protein forms a stable complex with NFS1, increases NFS1 activity, and is essential for the enzymatic activity of several Fe-S proteins $[19,20]$. Sulfur-containing defense compounds (SDCs) are involved in stress response and their synthesis involve several genes for sulfur assimilation [21].

It is hypothesized that soybean (Glycine max) has gone through at least two polyploidy and diploidization events, being considered a paleopolyploid [22], still presenting many gene duplications [23]. Various stresses can adversely affect plant growth and crop production, such as low temperature which modifies membrane lipid composition, thus affecting mitochondria respiratory function [24] and presumably photosynthesis. Expression of various plant genes is regulated by abiotic environmental stresses such as cold. Many cis-acting elements involved in stress response and stress-inducible genes contain cis-acting elements in their promoter regions have been described.

Here, we identified the soybean cysteine desulfurase genes by sequence comparison. Furthermore, we investigate the responsiveness of these genes under biotic and abiotic stresses, as well as transcript distribution in different tissues. Association between the high transcript level of mitochondrial genes, NFS1 and ISD11, and an increased expression of two cytosolic Fe-S proteins is showing here. Our data also demonstrate the relationship between the presence of specific cis-elements and regulation of transcript levels under various conditions.

\section{Results}

\section{Sequence analysis}

Comparative protein analyses showed that there are four cysteine desulfurase genes in G. max, corresponding to loci Glyma01g40510, Glyma09g02450, Glyma11g04800 and Glyma15g13350. These proteins can be classified into two groups: the first group is composed of IscS-like proteins, mitochondrial cysteine desulfurases, which are encoded by the genes located on chromosome 01 and 11 (NFS1_ChrO1 and NFS1_Chr11); the second group encompasses SufS-like proteins, plastid cysteine desulfurases, which are encoded by genes located on chromosome 9 and chromosome 15 (NFS2_ChrO9 and NFS2_Chr15). Soybean NFS1 genes share 94\% nucleic acid similarity and $98 \%$ protein identity, while NFS2 genes share $96 \%$ nucleic acid similarity and $97 \%$ protein identity. When compared to Arabidopsis thaliana sequences, NFS1 proteins have $76 \%$ protein identity, whereas NFS2 have $77 \%$. Pfam analysis demonstrated that all genes encode for an aminotransferase class- $\mathrm{V}$ motif and alignment analysis showed the location of a cysteine in the active site and a histidine and alanine in the cofactor binding site (Additional files 1 and 2). To find ISD11 genes, we used sequences from Saccharomyces cerevisiae and A. thaliana as queries against the Glyma1 genome. We found two loci that encode ISD11 orthologs, Glyma08g26490 and Glyma18g49970, showing $87 \%$ protein identity (Additional file 3). Soybean genes that encode NFS1, NFS2 and ISD11 appear at least twice on different chromosomes due to duplication events [25].

\section{Phylogenetic analysis}

Comparative amino acid analysis of IscS-like and SufSlike proteins of different plants and bacterial species showed that conserved regions varied from 54 to $98 \%$ and from 37 to $97 \%$ identity, respectively. A phylogenetic analysis of a wide range of organisms has shown that cysteine desulfurases form three independent clusters (Figure 1). One clade was composed by all sequences from the ISC system, and divided into monocots, dicots and bacteria, forming three subclades. The second cluster contained bacterial and algae sequences of cysteine desulfurases from the NIF system. The third clade was composed of proteins from the SUF system, and subdivided into three clades, showing the same branching as the ISC system. Some bacterial and all mitochondria located proteins clustered together; some bacterial, cyanobacterial and all plastid located proteins were also found in one cluster. This is in agreement with the endosymbiotic theory, which establishes a relationship between the endosymbiotic host and the bacterial ancestors [5]. 


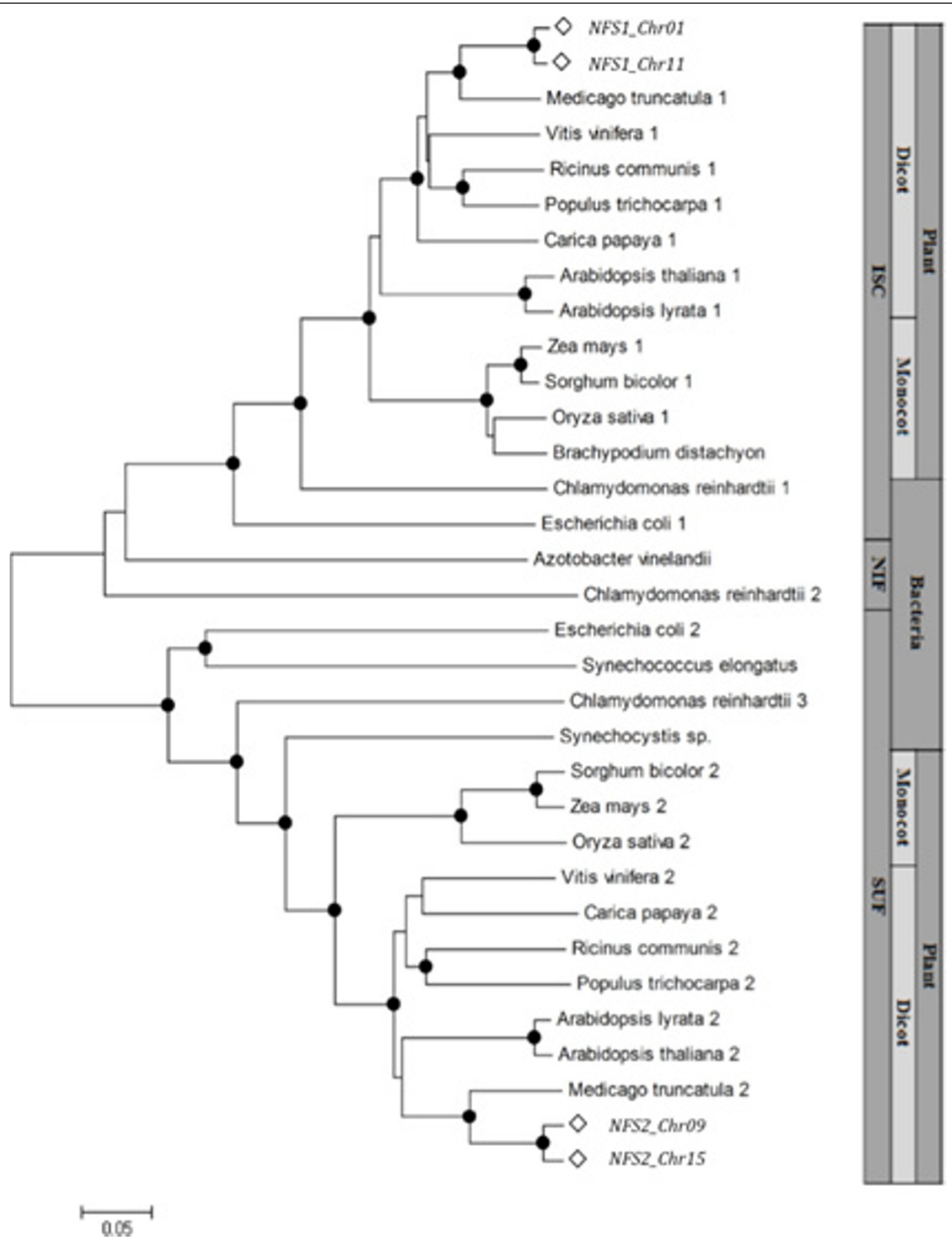

Figure 1 Phylogenetic analysis of cysteine desulfurase proteins. It is indicated to which [Fe-S] cluster biosynthesis systems (ISC, NIF and SUF) cysteine desulfurase belongs, and if this is a bacterial or plant (monocot or dicot) sequence. Black dots indicate bootstrap value higher than $80 \%$ 
Transcript analysis of cysteine desulfurases and ISD11 genes in soybean

Considering that $\mathrm{Fe}-\mathrm{S}$ proteins are involved in environmental or cellular sensing [5], quantitative RT-PCR was performed in order to investigate transcript levels of cysteine desulfurases and ISD11 in soybean. We designed gene-specific primers for NFS1_Chr01, NFS1_Chr11, NFS2_Chr09 and NFS2_Chr15 and analyzed the expression pattern of leaves and roots from non-treated plants and plants treated with salicylic acid (SA) and cold incubation. Further, to study whether ISD11 transcript levels are co-regulated with the NFS1 expression pattern, we performed a quantitative RT-PCR with nontreated and cold-treated plants. For all studied genes the transcript levels were normalized to the transcript levels of F-BOX and Metalloprotease [26].

In order to determine whether duplicated genes have differential expression profiles, we analyzed mRNA accumulation in control plants. These analyses showed that each cysteine desulfurase gene is individually expressed indicating a differential response to environmental stimuli. As the duplicated genes share a high degree amino acid identity, we summed expression levels from both copies to compare total NFS1 and NFS2 mRNA accumulation. While NFS1_ChrO1 is predominantly expressed in roots, we found higher NFS1_Chr11 transcript levels in leaves. In sum, a higher level is found in roots (Figure 2a). NFS2_Chr15 shows a higher expression in both organs as compared to NFS2_Chr09. NFS2_Chr09 transcripts mostly accumulate in roots and those of NFS2_Chr15 in leaves (Figure 2b). In both organs, ISD11_Chr18 shows a higher expression level than ISD11_Chr08. Taken together, a higher level was found in roots (Figure 2c). As shown in Genevestigator database, NFS1 is highly expressed in roots than in leaves in Arabidopsis thaliana, while NFS2 is predominantly expressed in leaves [27].

It appeared that cold-treated plants exhibited a differential response depending on the gene and tissue. In roots, NFS1_ChrO1 showed a higher expression than NFS1_Chr11 during the whole treatment. While NFS1_Chr01 transcript level decreased upon cold treatment, those of NFS1_Chr11 increased (Figure 3a). Sum analysis showed that total NFS1 mRNA in roots did not respond to cold treatment (Figure 3). In leaves, NFS1_Chr11 was higher expressed than NFS1_ChrO1 during the whole treatment. NFS1_Chr01 transcript level oscillated, and NFS1_Chr11 increased its expression during cold treatment (Figure 3b). Total NFS1 mRNA increased in leaves after cold incubation (Figure 3 ). These results corroborate with $A$. thaliana database, where leaves improve expression during cold treatment, while roots do not change [27]. Cold-treatment induced a decrease in both NFS2_ChrO9 and NFS2_Chr15

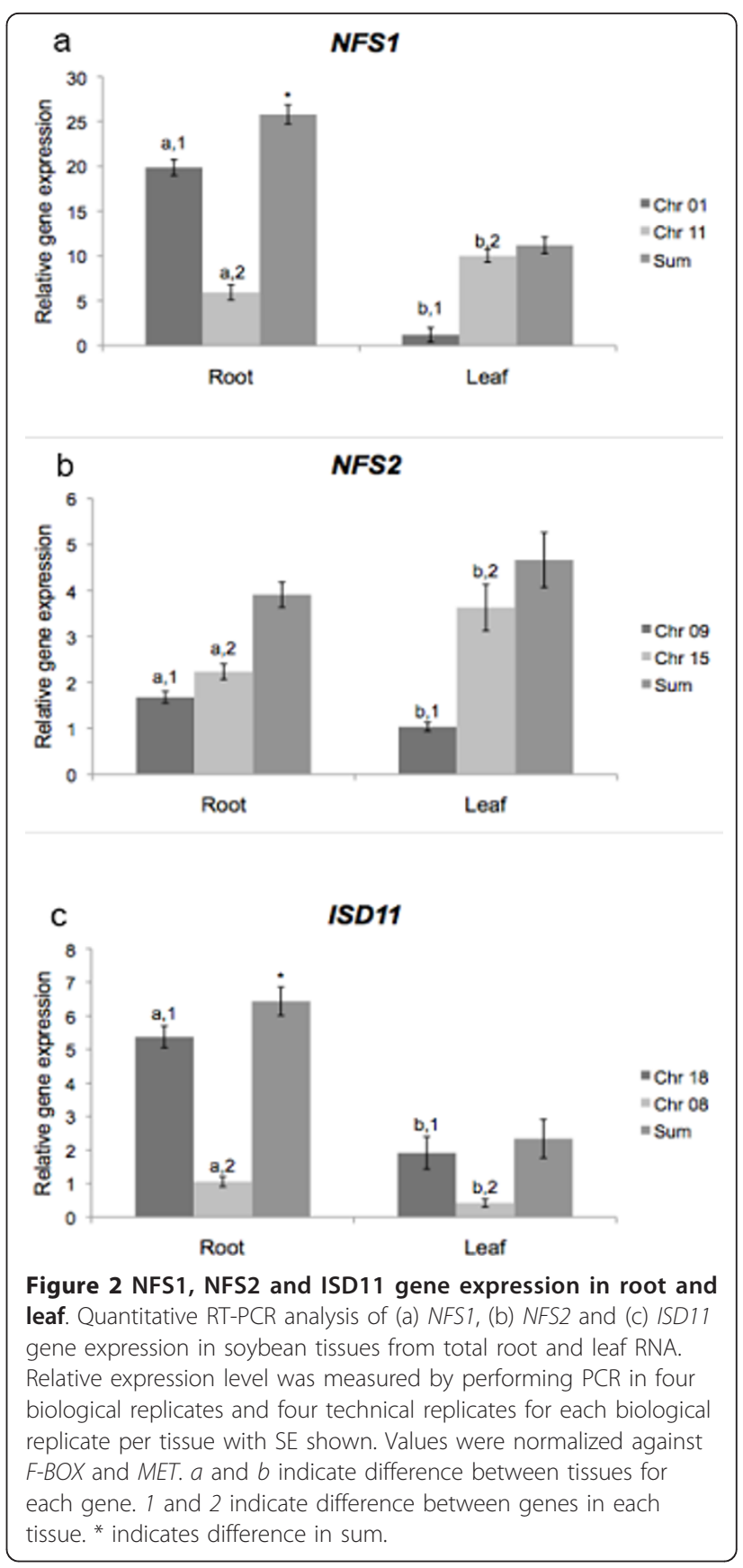

transcript levels in roots reaching a comparable expression level at 5, 10 and 24 h (Figure 3c) (Figure 3). In leaves, NFS2_Chr15 showed a higher expression level than NFS2_Chr09 during the whole treatment. While NFS2_ChrO9 transcript levels decreased, NFS2_Chr15 increased at $24 \mathrm{~h}$ (Figure 3d). Sum analysis showed that cold-treatment induced a decrease in NFS2 genes transcript levels (Figure 3). In roots, ISD11_Chr18 was higher expressed than ISD11_Chr08 during the whole treatment. While ISD11_Chr18 transcript levels increased were cold induced, ISD11_ChrO8 did not show 


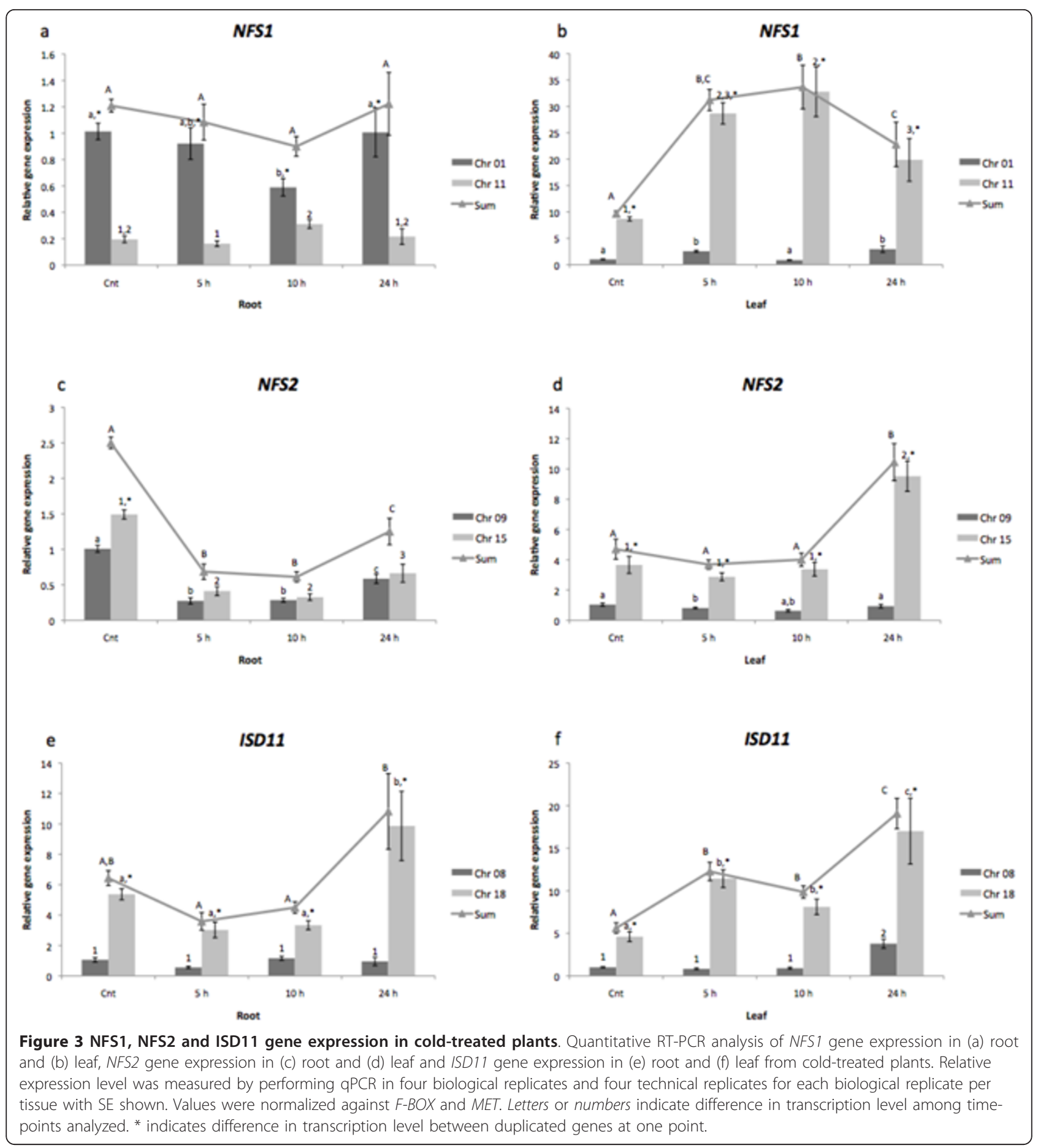

changes in expression (Figure 3e). Sum analysis revealed that total ISD11 mRNA initially decreased and then reached the former level in roots upon cold treatment (Figure 3). In leaves, ISD11_Chr18 showed a higher expression than ISD11_Chr08 during whole treatment, but both genes were upregulated upon cold treatment (Figure 3f).
When treated with $2 \mathrm{mM} \mathrm{SA}$, the response of cysteine desulfurase expression varies depending on tissue and gene. In roots, both NFS1 genes were upregulated upon SA incubation. Thus, sum analysis showed that NFS1 mRNA level after SA treatment was significantly higher than before (Figure 4a). In leaves, NFS1_ChrO1 decreased expression, while NFS1_Chr11 did not show 


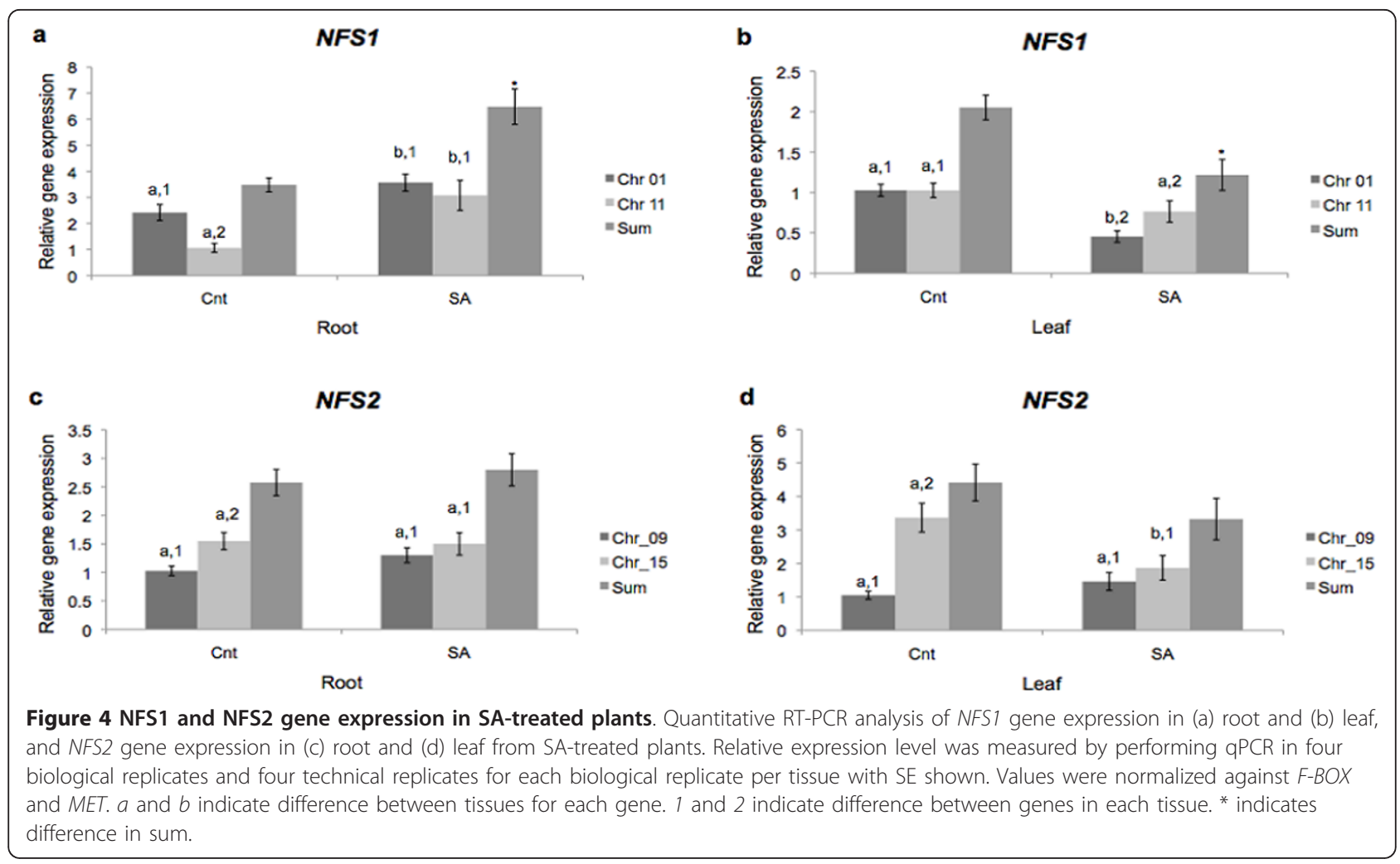

any changes. Total NFS1 mRNA level decreased due to SA treatment (Figure $4 \mathrm{~b}$ ). When $A$. thaliana were treated with $2 \mathrm{mM}$ SA during 24 hours, NFS1 expression was induced [27]. NFS2 transcript levels did not change in roots (Figure 4c). In leaves, NFS2_Chr15 showed a significant decrease in expression, while NFS2_Chr09 did not change. Sum analysis, for leaf, did not show any changes in expression (Figure 4d).

\section{Cis-elements search in promoter regions}

To identify putative cis-elements present in the NFS1 and NFS 2 promoters, we inspected the sequences 1,500 bp upstream of the transcriptional start site of all genes using the Plant Cis-Acting Regulatory Elements (PlantCARE) database [28]. The analysis identified a total of 178, 168, 163 and 151 hits for potential cis-elements putative transcription factor binding sites in NFS1_Chr01, NFS1_Chr11, NFS2_Chr09 and NFS2_Chr15, respectively. While some of the predicted cis-elements were present multiple times in the promoters, others occurred only once. All putative transcription factor binding sites with known function are shown in Table 1. Comparative analysis among cysteine desulfurase promoter regions showed sequence similarity between 8 and 66\%, and that the amount of shared ciselements varies from 38.2 to $76.9 \%$ (Figure 5). Comparing duplicated genes, they have a high promoter region similarity, and NFS1 and ISD11 promoters diverged less than those of NFS2 genes (Figure 5). The relationship between some motifs and our quantitative RT-PCR results are shown in Table 2.

\section{Coincidence of increased NFS1/ISD11 transcript levels and activities of cytosolic Fe-S enzymes}

Aldehyde oxidase (AO) catalyzes the conversion of an aldehyde to an acid and hydrogen peroxide in the presence of oxygen and water and Xanthine dehydrogenase $(\mathrm{XDH})$ catalyzes the hydrogenation of xanthine to urate. Both enzymes require FAD, molybdenum and two [2Fe$2 \mathrm{~S}$ ] clusters as cofactors. Therefore, $\mathrm{AO}$ and $\mathrm{XDH}$ activities are directly dependent on the mitochondrial [Fe-S] cluster assembly machinery. Hence, we analyzed the activity of $\mathrm{AO}$ and $\mathrm{XDH}$ using an in-gel activity assay [29]. In comparison to unstressed leaves, XDH activities were clearly enhanced upon cold treatment while AO activities increased only moderately under these conditions. Crude extract were obtained from three independent treatment (Figure 6), indicating that NFS1/ISD11 are required for $[\mathrm{Fe}-\mathrm{S}]$ cluster assembly on both proteins tested.

\section{Discussion}

Soybean is a paleopolypoid plant, whose polyploidisation may have occurred in the common ancestor of the 
Table 1 Transcription factor binding sites and motifs.

\begin{tabular}{|c|c|c|c|c|c|}
\hline Motifs & $\begin{array}{l}\text { NFS1 } \\
\text { Chr01 }\end{array}$ & $\begin{array}{l}\text { NFS1 } \\
\text { Chr11 }\end{array}$ & $\begin{array}{l}\text { NFS2 } \\
\text { Chro9 }\end{array}$ & $\begin{array}{l}\text { NFS2 } \\
\text { Chr15 }\end{array}$ & Function \\
\hline 3-AF1 binding site & & & $x$ & & light responsive element \\
\hline 5UTR Py-rich stretch & & $x(1)$ & $x(1)$ & $x(2)$ & cis-acting element conferring high transcription level \\
\hline ABRE & & & & $x$ & cis-acting element involved in the abscisic acid responsiveness \\
\hline ACE & $x$ & $x$ & & & cis-acting element involved in light responsiveness \\
\hline AE-box & $x$ & & & & part of a module for light response \\
\hline ARE & $x(1)$ & & $x(1)$ & $x(1)$ & cis-acting regulatory element essential for anaerobic induction \\
\hline as-2-box & & $x(1)$ & & $x(1)$ & involved in shoot-specific expression and light responsiveness \\
\hline AT- rich element & & $x$ & & & binding site of AT-rich DNA binding protein (ATBP-1) \\
\hline AT1-motif & & & & $x$ & part of a light responsive module \\
\hline ATCT-motif & $x$ & & & & part of a conserved DNA module involved in light responsiveness \\
\hline Box 4 & $x$ & $x$ & $x$ & $x$ & part of a conserved DNA module involved in light responsiveness \\
\hline Box 1 & $x$ & $x$ & $x$ & $x$ & light responsive element \\
\hline Box II & & & $x$ & & part of a light responsive element \\
\hline Box III & $x$ & & & & protein binding site \\
\hline Box W1 & & & $x$ & $x$ & fungal elicitor responsive element \\
\hline CAAT-box & $x$ & $x$ & $x$ & $x$ & common cis-element in promoter and enhancer regions \\
\hline CAT-box & & & $x$ & $x$ & cis-acting regulatory element related to meristem expression \\
\hline CATT-motif & & $x$ & & $x$ & part of a light responsive element \\
\hline CCAAT-box & & & $x$ & $x$ & MYBHV1 binding site \\
\hline CGTCA-motif & $x$ & $x$ & & & cis-acting regulatory element involved in MeJA-responsiveness \\
\hline chs-CMA2a & $x$ & & & & part of a light responsive element \\
\hline circadian & $x$ & $x$ & $x$ & & cis-acting regulatory element involved in circadian control \\
\hline ERE & & $x$ & & & ethylene-responsive element \\
\hline GAG-motif & $x$ & $x$ & & & part of a light responsive element \\
\hline GA-motif & $x$ & $x$ & $x$ & & part of a light responsive element \\
\hline GARE-motif & & $x$ & & $x$ & gibberillin-responsive element \\
\hline G-Box & & & $x$ & $x$ & cis-acting regulatory element involved in light responsiveness \\
\hline G-box & & & $x$ & $x$ & cis-acting regulatory element involved in light responsiveness \\
\hline GT1-motif & $x$ & & & & light responsive element \\
\hline HSE & & & & $x$ & cis-element involved in heat stress responsiveness \\
\hline LAMP-element & & $x$ & & & part of a light responsive element \\
\hline LS7 & & & & $x$ & part of a light responsive element \\
\hline MBS & $x(2)$ & $x(2)$ & $x(1)$ & $x(1)$ & MYB binding site involved in drought-inducibility \\
\hline MBSI & & $x$ & & & MYB binding site involved in flavonoid biosynthetic genes regulation \\
\hline MBSII & & $x$ & & & MYB binding site involved in flavonoid biosynthetic genes regulation \\
\hline motif 1 & & & & $x$ & cis-acting regulatory element root specific \\
\hline MRE & $x$ & $x$ & & & MYB binding site involved in light responsiveness \\
\hline P-box & & & & $x$ & gibberillin-responsive element \\
\hline sdOCT & $x$ & & & & cis-acting regulatory element related to meristem specific activation \\
\hline Skn-1 motif & $x$ & $x$ & $x$ & $x$ & cis-acting regulatory element required for endosperm expression \\
\hline Sp1 & & $x$ & $x$ & $x$ & light responsive element \\
\hline TATA-box & $x$ & $x$ & $x$ & $x$ & core promoter element around -30 of transcription start \\
\hline TCA- element & $x(1)$ & $x(2)$ & $x(2)$ & & cis-acting element involved in salicylic acid responsiveness \\
\hline TC-rich repeats & $x(2)$ & $x(3)$ & $x(2)$ & $x(2)$ & cis-acting responsive element involved in defense and stress responsiveness \\
\hline TCT-motif & & $x$ & $x$ & $x$ & part of a light responsive element \\
\hline TGACG-motif & $x$ & $x$ & & & cis-acting regulatory element involved in MeJA-responsiveness \\
\hline TGA-element & $x$ & $x$ & & & auxin-responsive element \\
\hline Total & 23 & 27 & 21 & 25 & \\
\hline
\end{tabular}

Transcription factor binding sites and number of motifs in each 1.500 bp upstream regions from transcription start site of soybean genes, according to PlantCARE database in default parameters.

* The motifs cited in Table 2 are marked in bold and the number inside parenthesis represent the time it appeared. 


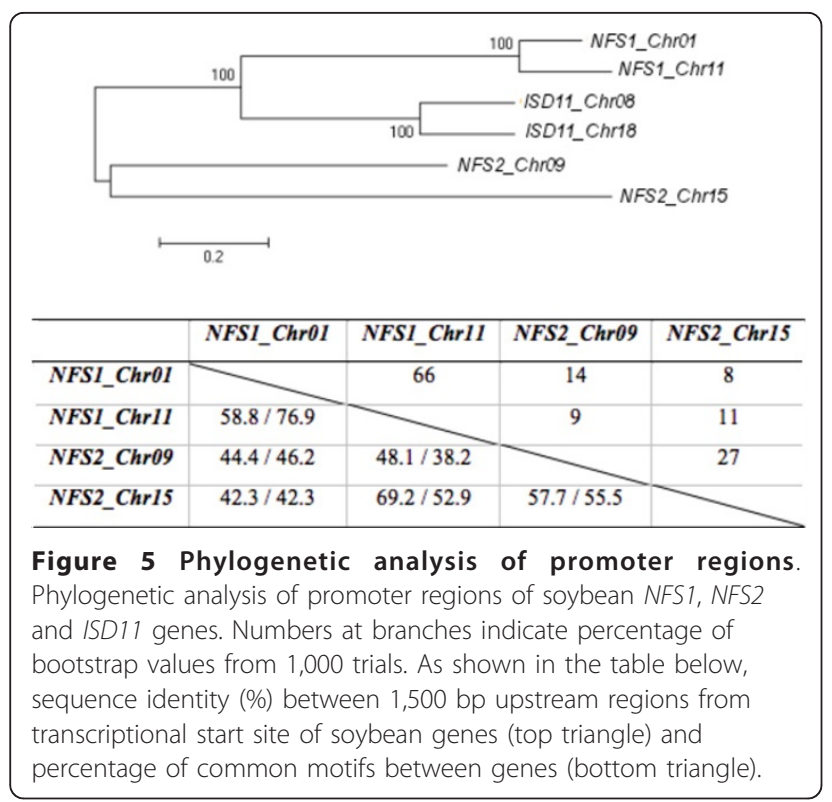

soybean and Medicago truncatula. In addition, it was suggested that a relatively recent polyploidy event occurred in the soybean lineage [22,30]. All analyzed genes are present in duplicate on different chromosomes showing a high degree of conservation and share important characteristics [25]. Due to the polyploidy events, mutations and gene rearrangements occurred, resulting in diversification of gene expression [31]. Here, we present the characterization of the promoters of soybean NFS1 and NFS2 genes, and identified tissue- and stressspecific response in expression of cysteine desulfurase and ISD11 genes both involved in [Fe-S] cluster biosynthesis.

Three different systems responsible for [Fe-S] cluster biosynthesis have been described [3], and involved genes appear to be conserved in bacteria, fungi, animals and plants [6,32]. In our phylogenetic analysis (Figure 1), it was possible to identify three distinct groups, composed of proteins from ISC, NIF and SUF systems. G. max protein sequences were located in plant clades near to M. truncatula. Comparing our phylogenetic approach and the described polyploidy events [30], it was possible to hypothesize that analyzed cysteine desulfurase genes were duplicated after the divergence of soybean and $M$. truncatula. Thus, soybean has two copies of each cysteine desulfurase gene, while $M$. truncatula has only one copy (Figure 1). Both species contain duplicated ISD11 genes (data not shown). Therefore, this polyploidy event may have occurred prior to divergence of both lines.

The present results suggest that NFS1 and NFS2 soybean genes, which encode proteins involved in sulfur assimilation and [Fe-S] cluster biosynthesis [16], are involved in response to cold stress and SA. Sulfur is an essential macronutrient which is assimilated to cysteine $[33,34]$, which will take part in the assembly of SDCs. When exposed to biotic and/or abiotic stress, synthesis of SDCs is induced via different signals, demonstrating their potential involvement in stress defense. There is an increased demand for cysteine as a precursor due to SDCs synthesis; therefore, the expression of genes for sulfur assimilation is induced [21]. Analyzing cold-treated plants, it is possible to observe that, in leaves, NFS1 and NFS2 genes increased transcript levels (Figure 3), perhaps due to SDCs stress response or due to its possible role in SDCs synthesis. When treated with SA, a simulator of biotic stress, NFS1 genes changed their expression pattern (Figure 4). In both experiments we observed a particular expression pattern, i.e. organs with primary contact to the stressor showed an increase in cysteine desulfurase transcript levels, while those less exposed showed a lower expression (Figures 3 and 4). This opposite profile may be due to a compensatory

Table 2 Relationship between motifs and qPCR.

\begin{tabular}{|c|c|c|c|}
\hline $\begin{array}{l}\text { Cis-element and } \\
\text { organism }^{\text {a }}\end{array}$ & Function & Gene & Correlation \\
\hline $\begin{array}{l}\text { 5UTR Py-rich stretch } \\
\text { Lycopersicon esculentum }\end{array}$ & $\begin{array}{l}\text { cis-acting element conferring high } \\
\text { transcription levels }\end{array}$ & $\begin{array}{l}\text { NFS1_Chr11, } \\
\text { NFS2_Chr15 }\end{array}$ & $\begin{array}{l}\text { NFS2_Chr15 is highly expressed in leaves and roots. } \\
\text { NFS1_Chr11 is highly expressed in leaves. }\end{array}$ \\
\hline ARE Zea mays & $\begin{array}{l}\text { cis-acting regulatory element essential for } \\
\text { the anaerobic induction }\end{array}$ & NFS1_Chro1 & $\begin{array}{l}\text { It is highly expressed in roots, where the } \mathrm{O}_{2} \text { availability is } \\
\text { low. }\end{array}$ \\
\hline MBS Arabidopsis thaliana & $\begin{array}{l}\text { MYB binding site involved in drought- } \\
\text { inducibility }\end{array}$ & All & $\begin{array}{l}\text { Drought stress effects are related to cold stress effects. All } \\
\text { genes respond to cold. }\end{array}$ \\
\hline $\begin{array}{l}\text { TC-rich repeats Nicotiana } \\
\text { tabacum }\end{array}$ & $\begin{array}{l}\text { cis-acting element involved in defense } \\
\text { and stress responsiveness }\end{array}$ & All & All genes respond to cold. \\
\hline $\begin{array}{l}\text { TCA-element } \\
\text { Brassica oleracea }\end{array}$ & $\begin{array}{l}\text { cis-acting element involved in salicylic } \\
\text { acid responsiveness }\end{array}$ & NFS1 genes & $\begin{array}{l}\text { Sum analysis showed that transcript level of NFS1 genes } \\
\text { vary in SA treatment. }\end{array}$ \\
\hline as-2-box Nicotiana tabacum & $\begin{array}{l}\text { involved in shoot-specific expression and } \\
\text { light responsiveness }\end{array}$ & $\begin{array}{l}\text { NFS1_Chr11, } \\
\text { NFS2_Chr15 }\end{array}$ & Both genes are highly expressed in leaves. \\
\hline
\end{tabular}

Putative transcription factor binding sites within the NFS1 and NFS2 promoters that showed correlation to our qPCR data.

a Organism where the cis-element was described, according to PlantCARE. 


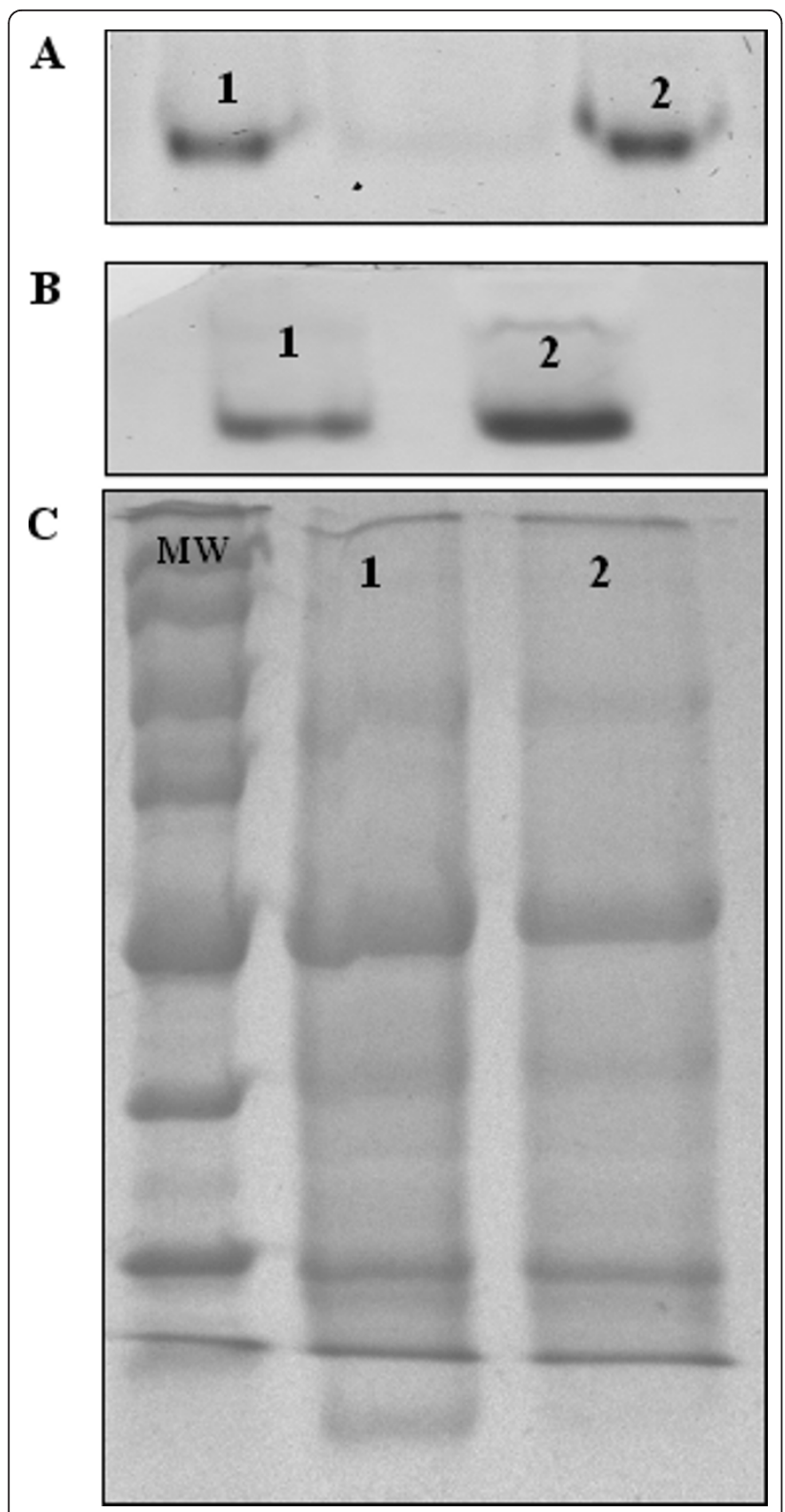

Figure 6 Cold stress effects on AO and XDH activity. (a) AO activity visualized by in situ staining after exposition of plants to cold stress for $18 \mathrm{~h}$. Wells were loaded with $100 \mu \mathrm{g}$ of protein of soybean wild type crude extracts of leaves from either untreated (1) or cold-stressed plants (2). Indole-3-carboxaldehyde plus 1-

naphthaldehyde were used as substrate. (b) XDH activity visualized by in situ staining after exposition of plants to cold stress for $18 \mathrm{~h}$. Wells were loaded with $100 \mu \mathrm{g}$ of protein of soybean wild type crude extracts of leaves from either untreated (1) or cold-stressed plants (2). Hypoxanthine was used as substrate. (c) SDS PAGE gel $12 \%$ staining with Comassie blue. MW; molecular weight (Broad Range Protein Molecular Marked from Promega); wells were loaded with $100 \mu \mathrm{g}$ of protein of soybean wild type crude extracts of leaves from either untreated (1) or cold-stressed plants (2). mechanism present in early stress response, and it may change if plants are exposed to longer stress periods.

When the plant cell are exposed to biotic or abiotic stress factors, modifications of the lipid composition of its membranes occur [35]. Soybean mitochondria show modifications in lipid content in response to low temperature [36], and this can alter respiratory properties and gene expression [24,37]. As many proteins involved in respiration, such as complexes I, II and III, are Fe-S proteins [4], a modification in the respiratory profile may change the requirement for proteins of the [Fe-S] cluster biosynthesis pathway, i.e. altering the expression of cysteine desulfurase genes. Stress dependent changes in gene expression occur in the cytoplasm as well as in chloroplasts. Whereas mitochondria developed an export system for [Fe-S] clusters that is essential for maturation of many nuclear and cytosolic proteins, [Fe$\mathrm{S}]$ cluster biosynthesis in mitochondria has a direct impact on protein activity, such as for aldehyde oxidase and xanthine dehydrogenase $[16,38,39]$ as shown in Figure 6 . The chloroplast is extremely sensitive to abiotic stress factors, such as elevated temperature and light, both increasing reactive oxygen species. Glutathione is involved in protection against oxidative damage triggered by biotic and abiotic stress in the cytosol and other cellular compartments. Synthesis of this peptide depends on sulfur assimilation and cysteine synthesis $[21,33,34]$, as this amino acid is the substrate of cysteine desulfurase $[14,40]$, a change in cysteine content may lead to a modification in its catalytic properties.

SA and its methylated form are involved in development, and are also fundamental for hypersensitive response and for systemic acquired resistance under biotic stress $[41,42]$. SA can induce the formation of reactive oxygen species, and these can react with various molecules in the cell, including lipids. As the organelle is often exposed to strong oxidative stress, some antioxidant enzymes should be simultaneously upregulated. An alternative oxidase has been proposed to represent a functional marker for mitochondrial dysfunction during biotic stress, and its content is increased in SA-treated soybean $[35,43]$. The treatment with SA causes mitochondrial dysfunction via oxidative stress causing changes in the cysteine desulfurase expression. This enzyme transfers electrons from reduced ubiquinone to molecular oxygen, bypassing complexes III and IV [24], and complex III contains [Fe-S] cluster [4]. In addition, SA-treated soybean altered the fatty acid composition of its mitochondria. As these organelles modified their membranes upon SA treatment, and cellular respiration 
involves Fe-S proteins, the expression of cysteine desulfurase may be altered under biotic stress.

The present quantitative RT-PCR results revealed a relationship between NFS1 and ISD11 transcript contents in roots and leaves as both genes showed a similar expression pattern (Figure 2). Moreover, to analyze whether an increase in NFS1 expression triggers an increase in ISD11 transcript levels, we studied ISD11 expression levels under cold stress. In roots, total ISD11 mRNA decreased during the treatment and recovered to the initial level after $24 \mathrm{~h}$, while NFS1 transcript levels did not change. In leaves, both genes were upregulated (Figure 3). The similarity in expression pattern between these genes may be explained by their function. NFS1 is a cysteine desulfurase involved in $[\mathrm{Fe}-\mathrm{S}]$ biosynthesis in mitochondria [6], whereas Isd11 was recently identified in yeast as a protein responsible for forming a stable complex with Nfs1 $[19,20]$. Besides interacting with the cysteine desulfurase, ISD11 showed in humans an important role in mitochondrial and cytosolic iron homeostasis [44] mediated by NFS1 [18]. Here, we demonstrated that interaction between mitochondrial genes NFS1/ISD11 increased expression and maturation of cytosolic enzymes XDH and AO. These results corroborate with data described for yeast, which associates the mitochondrial machinery for [Fe-S] cluster biosynthesis as being responsible for maturation of cytosolic $\mathrm{Fe}$ $\mathrm{S}$ proteins. Also, results in Figure 6, show, for the first time, a direct relation among increase expression of both cytosolic Fe-S protein (XDH and $\mathrm{AO}$ ) and mitochondrial cysteine desulfurase as a result of cold stress conditions. Moreover, our results are in agreement with the experiments involved co-expression of NFS1 and ISD11 of $A$. thaliana, which show a higher stability of NFS1 when co-expressed with ISD11 may suggesting that the interaction of NFS1/ISD11 promote the correct conformational structure of NFS1 (de Oliveira, LA and Frazzon, APG personal communication).

The soybean genome contains highly similar genes integrated in wider regulatory networks involved in differential regulation, including the presence of cis-acting regulatory elements in promoter regions [31]. Therefore, we analyzed DNA sequences to predict putative transcription factor binding sites located in the $-1500 \mathrm{bp}$ promoter regions. Duplicated genes have highly homologous promoter regions (Figure 5). When cis-elements were compared, all genes share high degree of common binding sites (Figure 5), suggesting that cysteine desulfurase genes share regulatory networks. In spite of this similarity, it has been shown that different environmental factors may trigger gene expression (Figures 2, 3 and 4). Since a complex molecular network is involved in regulation of gene expression and transcription factors are important components that lead to activation or repression of transcription [45], the differences observed may be due to the requirements of the corresponding factors in a particular tissue or organelle. The analysis of transcription factor binding sites provided an insight into transcript level data. Cis-elements related to quantitative RT-PCR experiments are shown in Table 2. A Py-rich element was found in NFS1_Chr11 and NFS2_Chr15 genes that showed high transcription levels in leaves and in both leaves and roots, respectively. An ARE element was found in NFS1_ChrO1, which displayed higher expression in roots than in leaves, whereas promoters with an as-2-box element showed higher expression in leaves. The TCA-element, related to SA response, was found in NFS1 genes that changed transcription pattern under this stress. Besides, all genes had cis-elements related to defense and stress (TC-rich) and to drought response $(M B S)$, and several genes are induced by both drought and cold stress, indicating a crosstalk between signaling pathways [46].

\section{Conclusions}

In this study, we carried out an analysis of cysteine desulfurase genes from soybean, which are involved in $[\mathrm{Fe}-\mathrm{S}]$ cluster biosynthesis. This study suggests that NFS1 and NFS2 genes are involved in stress response, and that their differential expression may be due to the presence of different cis-elements (Figure 7). Furthermore, ISD11 displayed an expression pattern similar to NFS1 genes, supporting a positive correlation in their activity. Our results provide the first insight into differential expression of duplicated genes involved in [Fe-S] cluster pathway, but further research is needed to determine whether other genes involved in $[\mathrm{Fe}-\mathrm{S}]$ cluster biogenesis follow this pattern.

\section{Methods}

\section{Identification of [Fe-S] cluster genes in soybean}

To identify cysteine desulfurase-encoding genes from the annotations of Glyma1 in the soybean genome, a similarity search method was performed. We used a protein sequence data set of known cysteine desulfurases from A. thaliana, Synechocystis sp. and Escherichia coli, and the modeled proteome data of annotated genes downloaded from Phytozome [47]. To confirm the protein identity, sequences were subjected to a profile search using Pfam [48]. Besides, the search results for each cysteine desulfurase were then applied to retrieve discovered regions as conserved active sites and cofactor binding amino acids. Other genes that encode proteins involved in [Fe-S] cluster biosynthesis, such as ISD11, were found using the strategy described above.

\section{Phylogenetic analysis}

Sequence alignments of cysteine desulfurase proteins were performed using ClustalX2 [49] with default 


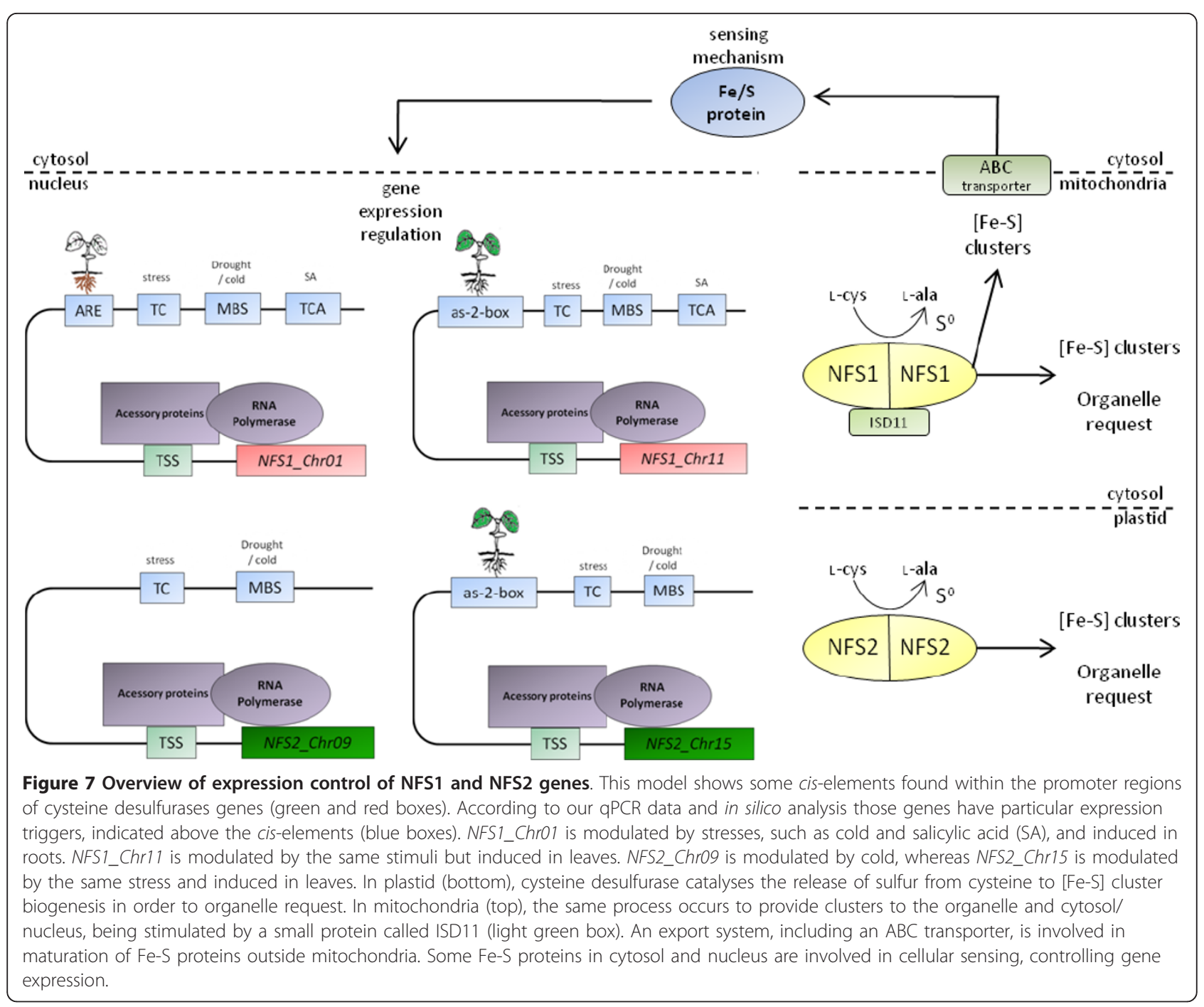

parameters and then visualized with GeneDoc Program [50]. Phylogenetic analysis was made with the Molecular Evolutionary Genetic Analysis (MEGA) Package Version 4.0 [51] with Neighbor-Joining method. Pairwise deletion was used to analyze gap and missing data in the alignments. The bootstrap test was performed with 1000 replications, and only the bootstraps values higher than $80 \%$ are displayed as black dots on the nodes. The species and their respective access numbers in Phytozome or NCBI database are as follows: G. $\max$ (Glyma01g40510/Glyma11g04800/Glyma09g02450/Glyma15g13350), Ricinus communis (XP_002531989/ XP_002523229), A. thaliana (At5g65720/At1g08490), Zea mays (ACF83040/NP_001130656), Oryza sativa (NP_001062914/EEC69110), Chlamydomonas reinhardtii (XP_001695008/XP_001701051/Au9.Cre12.g525650), Brachypodium distachyon (Bradi4g28300), Arabidopsis lyrata (XP_002864976/XP_002892460), Sorghum bicolor (Sb02g022360/Sb05g001270), Carica papaya (supercontig_129.49/supercontig_34.204), Vitis vinifera (XP_002274517/XP_002267920), M. truncatula (Medtr5g014960/Medtr3g105250), Populus trichocarpa (XP_002310363/XP_002314018), E. coli (YP_001458 463/NP_289087), Azotobacter vinelandii (YP_00279 7401), Synechococcus elongates (NP_665776) and Synechocystis sp. (NP_442475).

\section{DNA sequence analysis}

To predict the transcription factor binding sites located in the -1500 bp promoter regions of each soybean analyzed gene, we retrieved the -1500 bp upstream sequence from the putative transcription start site for each gene from the Glymal annotation. After that, the analysis of each promoter region was performed using the Plant Cis-Acting Regulatory Elements (PlantCARE) database [28]. Phylogenetic analysis of promoter regions was performed as described above, and percentage of bootstrap values are shown at branches. 


\section{Plant material and treatments}

To study the responsiveness of cysteine desulfurase genes under stress, two different experiments were performed. For cold and SA treatments, we used the soybean (G. max [L.] Merr.) cv. IAS-5 and cv. Conquista seeds, respectively. Plants were grown in plastic pots (3 seeds per pot), filled with vermiculite and solution of half-strength MS medium [52], in a controlled environment growth chamber at $16 / 8$ $\mathrm{h}$ of day/night $\left(22.5 \mu \mathrm{mol} \mathrm{m} \mathrm{s}^{-2}\right)$ photoperiod at $28 \pm 1^{\circ}$ C. For cold treatment, after 11 days, seedlings were transferred to a plastic pot, under the same conditions, containing one seedling. At the age of 27 days, plants were submitted to cold stress at $4^{\circ} \mathrm{C}$ for $0,5,10$ and 24 hours. For SA treatment, plants were kept for 14 days in vermiculite, and then transferred to a hydroponic solution (halfstrength MS medium) with additional $2 \mathrm{mM}$ SA for $48 \mathrm{~h}$. Control plants were submitted to the same conditions without SA addition. After both treatments, root and leaf tissues were collected, frozen in liquid nitrogen and stored at $-80^{\circ} \mathrm{C}$ till further use. All the analyses were performed in biological quadruplicates.

\section{RNA isolation and quantitative RT-PCR}

To study the expression of cysteine desulfurase genes, samples from control and treated plants were collected ( $n=4$ per each group). Total RNA was isolated from frozen tissues by extraction with Trizol (Invitrogen) according to the manufacturer's instructions and quality was evaluated by electrophoresis on a 1\% agarose gel. Prior to quantitative RT-PCR, RNA samples were treated with DNase I (Promega) at $37^{\circ} \mathrm{C}$ for $30 \mathrm{~min}$. Reverse transcription reactions were performed using the $\mathrm{M}$ MLV reverse transcriptase (Invitrogen) following manufacturer's instructions.

Quantitative RT-PCR was conducted in an ABI 7500 Real-Time PCR System (Applied Biosystem) using SYBR Green I (Invitrogen) to detect double-strand cDNA synthesis. Soybean F-BOX (F-Box protein family) and $M E T$ (insulin-degrading enzyme, metalloprotease) genes were used as reference genes for data normalization and to calculate the relative mRNA levels. Reactions were done in a volume of $20 \mu \mathrm{L}$ containing $10 \mu \mathrm{L}$ of cDNA, $0.1 \times$ SYBR Green I (Invitrogen), $0.025 \mathrm{mM}$ dNTP, $1 \times$ PCR Buffer, 3 $\mathrm{mM} \mathrm{MgCl} 2,0.25 \mathrm{U}$ Platinum Taq DNA Polimerase (Invitrogen), and $200 \mathrm{nM}$ of each reverse and forward primers. A negative control without cDNA template was included for each primer combination. Primer sequences for quantitative RT-PCR were as follows: for NFS1_Chr01, NFS1_01R 5'-CCTCCCAATTCTCTCCATCGGT-3', and for NFS1_Chr11, NFS1_11R 5'-CCTCCCAATTTCCTCCATGGGC-3' with the same forward primer NFS1F 5'CGGAGCACAAGTGCGTCC-3'; for NFS2_Chr09, NFS2_09R 5'-CCCGTGCACTTGAGCTGACA-3', and for NFS2_Chr15, NFS2_15R
CACGTGCACTTGAGCTGACG-3' with the same forward primer NFS2F 5'-GTCGAACGAGCTGCCCTTTG3'; for ISD11_Chr08, ISD11_08R 5'- CGCTGCGGAGCGGAGAAT-3', and for ISD11_Chr18, ISD11_18R 5'TTGCGGAGCGGAGGGG -3' with the same forward primer ISD11F 5'-TCCACCGCCTTCGCCC-3'. These primers set generated amplicon sizes of 200, 157 and 91 and 89 bp for NFS1, NFS2 and ISD11, respectively (Additional file 4). The conditions were set as follows: an initial step for polymerase activation for $5 \mathrm{~min}$ at $94^{\circ} \mathrm{C}, 40$ cycles of $15 \mathrm{~s}$ at $94^{\circ} \mathrm{C}$ for denaturation, $10 \mathrm{~s}$ at $60^{\circ} \mathrm{C}$ for annealing, and $15 \mathrm{~s}$ at $72^{\circ} \mathrm{C}$ for elongation, followed by a meltingcurve analysis and fluorescence measured from 60 to $95^{\circ}$ C. Four biological replicates and four technical replicates for each biological replicate were used.

\section{Activity assays}

Total proteins extract from untreated and cold stress treatment tissue were obtained from plants grown in the same conditions as described for quantitative RT-PCR. Protein quantification was performed by Bradford assay (BioRad) and equal amount $(100 \mu \mathrm{g})$ of protein was applied in a $7.5 \%$ native PAGE gel, $\mathrm{AO}$ and $\mathrm{XDH}$ were detected by activity staining previously described $[29,53]$

\section{Data analysis}

Threshold and baselines were manually determined using the ABI 7500 Real-Time PCR SDS Software v2.0. To analyze the relative cysteine desulfurases $\mathrm{mRNA}$ expression relative to the constitutive genes, we used the $2^{-\Delta \Delta C t}$ method [54]. Student's $t$ test was performed to compare pairwise differences in gene expression, following the two samples assuming unequal variances and two-tailed distribution parameters. For time-course treatment, 1-way ANOVA and Duncan post hoc analysis were performed using SPSS17. The means were considered significantly different when $P<0.05$.

\section{Additional material}

Additional file 1: Alignment of IscS-like. Alignment of soybean

cysteine desulfurase homologue to IscS from Escherichia coli. * indicates residues from active and from cofactor binding sites. \# indicates amino acids residues that differ between soybean duplicated genes.

Additional file 2: Alignment of SufS-like. Alignment of soybean cysteine desulfurase homologue to SufS from Escherichia coli. * indicates residues from active and from cofactor binding sites. \# indicates amino acids residues that differ between soybean duplicated genes.

Additional file 3: Alignment of ISD11 proteins. Alignment of soybean, Arabidopsis thaliana and Saccharomyces cerevisiae ISD11 proteins.

Additional file 4: Primer sequences. Primer sequences and amplicon characteristics for each gene.

\section{Acknowledgements}

We are very grateful to Prof. Giancarlo Pasquali and Prof. Márcia P. Margis from UFRGS for laboratorial and technical support. We also thank Prof. Jörg 
Meurer (Ludwig-Maximilians-University, Munich, Germany) for his editing of the manuscript. This work was supported by Conselho Nacional de Desenvolvimento Científico e Tecnológico (CNPq- \#302471/2009-0, \#4703882009-9 and \#473769/2007-7) of Brazil, and the Coordenação de Aperfeiçoamento de Pessoal de Nivel Superior (PDEE/CAPES) of Brazil.

\section{Author details}

'Biotechnology Center, Federal University of Rio Grande do Sul - UFRGS, Porto Alegre, RS, Brazil. '2Department of Microbiology, Federal University of Rio Grande do Sul - UFRGS, Porto Alegre, RS, Brazil. ${ }^{3}$ Department of Food Science, Federal University of Rio Grande do Sul - UFRGS, Porto Alegre, RS, Brazil.

\section{Authors' contributions}

MDH carried out the quantitative RT-PCR analysis, sequence alignment, phylogenetic studies, cis-elements search, and performed the statistical analysis and drafted the manuscript. EMD performed the AO and XDS assays. LAO grow the plants and performed the RNA extraction and preparation of CDNA. APGF participated in the design of the study and coordination. RM performed the statistical analysis, participated in the design of the study and coordination. JF participated in the design and coordination of the study and gave the final approved. All authors read and approved the final manuscript.

Received: 23 July 2011 Accepted: 18 November 2011 Published: 18 November 2011

\section{References}

1. Ayala-Castro C, Saini A, Outten FW: Fe-s cluster assembly pathways in bacteria. Microbiology and Molecular Biology Reviews 2008, 72(1):110

2. Muhlenhoff $U$, Lill R: Biogenesis of iron-sulfur proteins in eukaryotes: a novel task of mitochondria that is inherited from bacteria. Biochimica Et Biophysica Acta-Bioenergetics 2000, 1459(2-3):370-382.

3. Johnson DC, Dean DR, Smith AD, Johnson MK: Structure, function, and formation of biological iron-sulfur clusters. Annual Review of Biochemistry 2005, 74:247-281.

4. Lill R, Muhlenhoff $\mathrm{U}$ : Maturation of iron-sulfur proteins in eukaryotes: Mechanisms, connected processes, and diseases. Annual Review of Biochemistry 2008, 77:669-700.

5. Lill R: Function and biogenesis of iron-sulphur proteins. Nature 2009, 460(7257):831-838.

6. Balk J, Lobreaux S: Biogenesis of iron-sulfur proteins in plants. Trends in Plant Science 2005, 10(7):324-331.

7. Schwenkert S, Netz DJA, Frazzon J, Pierik AJ, Bill E, Gross J, Lill R, Meurer J: Chloroplast HCF101 is a scaffold protein for [4Fe-4S] cluster assembly. Biochemical Journal 2010, 425:207-214.

8. Takahashi Y, Tokumoto U: A third bacterial system for the assembly of iron-sulfur clusters with homologs in archaea and plastids. Journal of Biological Chemistry 2002, 277(32):28380-28383.

9. Jacobson MR, Cash VL, Weiss MC, Laird NF, Newton WE, Dean DR: Biochemical and Genetic-Analysis of the Nifusvwzm Cluster from Azotobacter-Vinelandii. Molecular \& General Genetics 1989, 219(1-2):49-57.

10. Zheng $L M$, Cash VL, Flint DH, Dean DR: Assembly of iron-sulfur clusters Identification of an iscSUA-hscBA-fdx gene cluster from Azotobacter vinelandii. Journal of Biological Chemistry 1998, 273(21):13264-13272.

11. Kushnir S, Babiychuk E, Storozhenko S, Davey MW, Papenbrock J, De Rycke R, Engler G, Stephan UW, Lange $H$, Kispal $G$, et al: A mutation of the mitochondrial $A B C$ transporter Sta1 leads to dwarfism and chlorosis in the Arabidopsis mutant starik. Plant Cell 2001, 13(1):89-100.

12. Van Hoewyk D, Abdel-Ghany SE, Cohu CM, Herbert SK, Kugrens P, Pilon M, Pilon-Smits EAH: Chloroplast iron-sulfur cluster protein maturation requires the essential cysteine desulfurase CpNifS. Proceedings of the National Academy of Sciences of the United States of America 2007, 104(13):5686-5691.

13. Ye H, Pilon M, Pilon-Smits EAH: CpNifS-dependent iron-sulfur cluster biogenesis in chloroplasts. New Phytologist 2006, 171(2):285-292.

14. Zheng LM, White RH, Cash VL, Dean DR: Mechanism for the Desulfurization of L-Cysteine Catalyzed by the Nifs Gene-Product. Biochemistry 1994, 33(15):4714-4720.

15. Zheng LM, White RH, Cash VL, Jack RF, Dean DR: Cysteine Desulfurase Activity Indicates a Role for Nifs in Metallocluster Biosynthesis.
Proceedings of the National Academy of Sciences of the United States of America 1993, 90(7):2754-2758.

16. Frazzon APG, Ramirez MV, Warek U, Balk J, Frazzon J, Dean DR, Winkel BSJ: Functional analysis of Arabidopsis genes involved in mitochondrial ironsulfur cluster assembly. Plant Molecular Biology 2007, 64(3):225-240.

17. Godman J, Balk J: Genome analysis of Chlamydomonas reinhardtii reveals the existence of multiple, compartmentalized iron-sulfur protein assembly machineries of different evolutionary origins. Genetics 2008, 179(1):59-68.

18. Rouault TA, Tong WH: Iron-sulphur cluster biogenesis and mitochondrial iron homeostasis. Nature Reviews Molecular Cell Biology 2005, 6(4):345-351.

19. Wiedemann N, Urzica E, Guiard B, Muller H, Lohaus C, Meyer HE, Ryan MT, Meisinger $C$, Muhlenhoff $U$, Lill R, et al: Essential role of Isd11 in mitochondrial iron-sulfur cluster synthesis on Isu scaffold proteins. Embo Journal 2006, 25(1):184-195.

20. Adam AC, Bornhovd C, Prokisch H, Neupert W, Hell K: The Nfs1 interacting protein Isd11 has an essential role in $\mathrm{Fe} / \mathrm{S}$ cluster biogenesis in mitochondria. Embo Journal 2006, 25(1):174-183.

21. Rausch $T$, Wachter A: Sulfur metabolism: a versatile platform for launching defence operations. Trends in Plant Science 2005, 10(10):503-509.

22. Kim KD, Shin JH, Van K, Kim DH, Lee SH: Dynamic Rearrangements Determine Genome Organization and Useful Traits in Soybean. Plant Physiology 2009, 151(3):1066-1076.

23. Shoemaker RC, Schlueter J, Doyle JJ: Paleopolyploidy and gene duplication in soybean and other legumes. Current Opinion in Plant Biology 2006, 9(2):104-109.

24. Matos AR, Hourton-Cabassa C, Cicek D, Reze N, Arrabaca JD, Zachowski A, Moreau F: Alternative oxidase involvement in cold stress response of Arabidopsis thaliana fad2 and FAD3+ cell suspensions altered in membrane lipid composition. Plant and Cell Physiology 2007, 48(6):856-865.

25. Mochida K, Yoshida T, Sakurai T, Yamaguchi-Shinozaki K, Shinozaki K, Tran LSP: In silico Analysis of Transcription Factor Repertoire and Prediction of Stress Responsive Transcription Factors in Soybean. DNA Research 2009, 16(6):353-369.

26. Libault M, Thibivilliers S, Bilgin D, Radwan O, Benitez M, Clough S, Stacey G: Identification of four soybean reference genes for gene expression normalization. Plant Genome 2008, 1:44-54.

27. Hruz T, Laule O, Szabo G, Wessendorp F, Bleuler S, Oertle L, Widmayer P, Gruissem W, Zimmermann P: Genevestigator v3: a reference expression database for the meta-analysis of transcriptomes. Adv Bioinformatics 2008, 2008:420747.

28. Lescot M, Dehais P, Thijs G, Marchal K, Moreau Y, Van de Peer Y, Rouze P, Rombauts S: PlantCARE, a database of plant cis-acting regulatory elements and a portal to tools for in silico analysis of promoter sequences. Nucleic Acids Research 2002, 30(1):325-327.

29. Bittner $F$, Oreb M, Mendel RR: ABA3 is a molybdenum cofactor sulfurase required for activation of aldehyde oxidase and xanthine dehydrogenase in Arabidopsis thaliana. Journal of Biological Chemistry 2001, 276(44):40381-40384.

30. Pfeil BE, Schlueter JA, Shoemaker RC, Doyle JJ: Placing paleopolyploidy in relation to taxon divergence: A phylogenetic analysis in legumes using 39 gene families. Systematic Biology 2005, 54(3):441-454.

31. Yi JX, Derynck MR, Chen L, Dhaubhadel S: Differential expression of CHS7 and CHS8 genes in soybean. Planta 2010, 231(3):741-753.

32. Frazzon J, Dean DR: Formation of iron-sulfur clusters in bacteria: an emerging field in bioinorganic chemistry. Current Opinion in Chemical Biology 2003, 7(2):166-173.

33. Saito K: Sulfur assimilatory metabolism. The long and smelling road. Plant Physiology 2004, 136(1):2443-2450.

34. Biswal B, Raval M, Biswal U, Joshi P: Response of Photosynthetic Organelles to Abiotic Stress: Modulation by Sulfur Metabolism. Sulfur Assimilation and Abiotic Stress in Plants Berlin/Heidelberg: Springer; 2008, 167-191.

35. Matos AR, Mendes AT, Scotti-Campos P, Arrabaca JD: Study of the effects of salicylic acid on soybean mitochondrial lipids and respiratory properties using the alternative oxidase as a stress-reporter protein. Physiologia Plantarum 2009, 137(4):485-497.

36. de Virville JD, Cantrel C, Bousquet AL, Hoffelt M, Tenreiro AM, Pinto W, Arrabaca JD, Caiveau O, Moreau F, Zachowski A: Homeoviscous and 
functional adaptations of mitochondrial membranes to growth temperature in soybean seedlings. Plant Cell and Environment 2002, 25(10):1289-1297.

37. Caiveau O, Fortune D, Cantrel C, Zachowski A, Moreau F: Consequences of omega-6-oleate desaturase deficiency on lipid dynamics and functional properties of mitochondrial membranes of Arabidopsis thaliana. Journal of Biological Chemistry 2001, 276(8):5788-5794.

38. Mendel RR, Bittner F: Cell biology of molybdenum. Biochimica et Biophysica Acta 2006, 1763:621-635.

39. Teschner J, Lachmann N, Schulze J, Geisler M, Selbach K, SantamariaAraujo J, Balk J, Mendel RR, Bittner F: A Novel Role for Arabidopsis Mitochondrial ABC Transporter ATM3 in Molybdenum Cofactor Biosynthesis. The Plant Cell 2010, 22:468-480.

40. Mihara $\mathrm{H}$, Esaki N: Bacterial cysteine desulfurases: their function and mechanisms. Applied Microbiology and Biotechnology 2002, 60(1-2):12-23.

41. Durrant WE, Dong X: Systemic acquired resistance. Annual Review of Phytopathology 2004, 42:185-209.

42. Dong XN: NPR1, all things considered. Current Opinion in Plant Biology 2004, 7(5):547-552.

43. Amirsadeghi S, Robson CA, Vanlerberghe GC: The role of the mitochondrion in plant responses to biotic stress. Physiologia Plantarum 2007, 129(1):253-266.

44. Shi Y, Ghosh MC, Tong WH, Rouault TA: Human ISD11 is essential for both iron-sulfur cluster assembly and maintenance of normal cellular iron homeostasis. Human Molecular Genetics 2009, 18:3014-3025.

45. Qiu P: Recent advances in computational promoter analysis in understanding the transcriptional regulatory network. Biochemical and Biophysical Research Communications 2003, 309(3):495-501.

46. Shinozaki K, Yamaguchi-Shinozaki K, Seki M: Regulatory network of gene expression in the drought and cold stress responses. Current Opinion in Plant Biology 2003, 6(5):410-417.

47. Phytozome. [http://www.phytozome.net].

48. Finn RD, Mistry J, Tate J, Coggill P, Heger A, Pollington JE, Gavin OL, Gunasekaran P, Ceric G, Forslund K, et al: The Pfam protein families database. Nucleic Acids Research 2010, 38:D211-D222.

49. Larkin MA, Blackshields G, Brown NP, Chenna R, McGettigan PA, McWilliam H, Valentin F, Wallace IM, Wilm A, Lopez R, et al: Clustal W and clustal X version 2.0. Bioinformatics 2007, 23(21):2947-2948.

50. The GeneDoc Program. [http://www.nrbsc.org/gfx/genedoc/].

51. Tamura K, Dudley J, Nei M, Kumar S: MEGA4: Molecular evolutionary genetics analysis (MEGA) software version 4.0. Molecular Biology and Evolution 2007, 24(8):1596-1599.

52. Murashige T, Skoog F: A Revised Medium for Rapid Growth and Bio Assays with Tobacco Tissue Cultures. Physiologia Plantarum 1962, 15(3):473-\&.

53. Koshiba T, Saito E, Ono N, Yamamoto N, Sato M: Purification and properties of flavin- and molybdenum-containing aldehyde oxidase from coleoptiles of maize. Plant Physiology 1996, 110(3):781-789.

54. Livak KJ, Schmittgen TD: Analysis of relative gene expression data using real-time quantitative PCR and the 2(T)(-Delta Delta C) method. Methods 2001, 25(4):402-408.

doi:10.1186/1471-2229-11-166

Cite this article as: Heis et al:: Differential expression of cysteine desulfurases in soybean. BMC Plant Biology 2011 11:166.

\section{Submit your next manuscript to BioMed Central and take full advantage of:}

- Convenient online submission

- Thorough peer review

- No space constraints or color figure charges

- Immediate publication on acceptance

- Inclusion in PubMed, CAS, Scopus and Google Scholar

- Research which is freely available for redistribution

Submit your manuscript at www.biomedcentral.com/submit 